\title{
José Majojo e Francisco Moçambique, marinheiros das rotas atlânticas: notas sobre a reconstituição de trajetórias da era da abolição.
}

\author{
Beatriz Gallotti Mamigonian
}

José e Francisco apareceram primeiro numa listagem preparada pela legação britânica no Rio de Janeiro das 52 pessoas que seguiriam dali para Trinidad, no Caribe, a bordo do navio Despatch, fretado pelos oficiais da legação no fim de 1846 para levar africanos emancipados e seus filhos para o lugar onde pudessem, como insistiam os ingleses, "desfrutar da plena liberdade". Mais tarde, em outra documentação também pertencente ao Ministério das Relações Exteriores britânico (Foreign Office), as circunstâncias em que os dois africanos se tornaram protegidos do governo de Sua Majestade Britânica ficaram mais claras: eles eram marinheiros a bordo do Dois de Fevereiro, navio que fazia a rota Rio de JaneiroBenguela, quando este foi apreendido, em 1841, pelo cruzador da marinha britânica Fawn durante a campanha de repressão ao tráfico de escravos na costa brasileira. Escravos de Antônio Gonçalves da Luz, eles foram reclamados por caminhos diplomáticos, e essa longa negociação gerou registros que hoje nos permitem discutir suas trajetórias de vida, aparentemente incomuns, mas próprias da era da abolição. Os dois homens, que depois viriam a ser identificados como José Majojo e Francisco Moçambique, foram embarcados como escravos na costa oriental da África. Do Índico atravessaram o Atlântico e desembarcaram no Rio de Janeiro, onde foram vendidos. Sabemos que foram engajados como marinheiros, o que os levou para várias partes do Atlântico, inclusive Benguela. Entretanto, depois de caírem na malha abolicionista britânica, acabaram no Caribe; Francisco com passagem pelo Cabo da Boa Esperança. ${ }^{1}$

Casos individuais e listagens nominais povoam arquivos; no entanto, poucos pesquisadores aceitam o desafio de trazê-los à luz como algo mais do que mera ilustração de histórias já conhecidas. Este artigo tem três objetivos interligados: seguir os passos de José Majojo e de Francisco Moçambique para discutir as fontes primárias que permitem que saibamos de suas vidas; sondar as possibilidades oferecidas pela documentação fragmentária para reconstituir trajetórias; e refletir sobre os significados metodológicos desse procedimento.

\section{Indivíduos e questões de método}

O uso de biografias e de trajetórias de vida na historiografia não é novo, mas tem tido desdobramentos importantes nas últimas décadas. Destaco aqui alguns deles. Em primeiro lugar, seguir indivíduos tem servido aos historiadores como recurso metodológico para observar de perto o desenrolar dos processos históricos e, especialmente, devolver a eles protagonismo e indeterminação. Isso porque, no conjunto, os registros individuais revelam as alternativas disponíveis aos indivíduos em dado momento histórico, as escolhas que fizeram e, em última instância, seu impacto na história. Em segundo lugar, esse procedimento tem facilitado aos historiadores aproximar-se dos indivíduos pertencentes a grupos silenciados pela história, ou anônimos, frequentemente a maioria. Num primeiro momento, essa aproximação de determinados grupos se fez de forma quantitativa, com dados agregados, mas de algum tempo para cá os historiadores atentos às "classes subalternas" têm-se preocupado em distinguir os indivíduos e identificar diferenças no seio do grupo do qual faziam parte. O objetivo principal é resgatar

\footnotetext{
* Este texto foi apresentado em conferências em Moçambique e no Brasil, e baseou-se em pesquisa realizada em diferentes momentos, o mais recente deles uma missão de pesquisa financiada pelo acordo CAPES/Cofecub no 527/2006, Modernidades Alternativas. Gostaria de agradecer a Manolo Florentino pelos convites para discussão e a Henrique Espada Lima pelos comentários que me ajudaram a revisar o texto, guardando responsabilidade pelas imperfeições.
} 
do esquecimento as experiências daqueles que não deixaram seus próprios registros nem ficaram marcados na memória coletiva. Ainda assim, o uso de histórias individuais não serve para fins biográficos propriamente, exceto em raros casos. ${ }^{2}$

Seguir pessoas no passado exige dos historiadores, necessariamente, um preparo para a investigação nominativa em fontes fragmentadas. É bem verdade que, na maioria dos casos, parte-se de processos eclesiásticos ou judiciais que iluminam determinados indivíduos e sugerem uma investigação mais aprofundada de suas trajetórias. Assim se passou com Carlos Ginzburg ao eleger o caso de Menocchio, o moleiro friulano que caiu nas malhas da Inquisição por suas ideias pouco convencionais sobre a criação do mundo, analisado em $O$ queijo e os vermes. ${ }^{3}$ Mas, de outro método partiu Alain Corbin ao escolher discutir a trajetória de Louis-François Pinagot, o artesão-tamanqueiro que não foi alvo de processos nem deixou um único registro de suas ideias, não se afastando de seus contemporâneos quase anônimos, identificados apenas pelos registros oficiais obrigatórios. Além do fato de ter tido vida longa na França oitocentista, Corbin escolheu Pinagot justamente por ser "mediano": nem rico nem miserável, em nada excepcional. ${ }^{4}$

Fica claro que um dos principais problemas do historiador que toma um indivíduo por foco central de sua narrativa é o de discutir a representatividade da escolha deste em relação ao tema central. Para se tirar conclusões sobre a cultura popular no Quinhentos, até que ponto Menocchio podia ser considerado um camponês típico da Friulia se ele era dos poucos alfabetizados? Carlo Gizburg se apoia em Edoardo Grendi, que cunhou a expressão "excepcional normal" para tratar desses casos que, aparentemente desviantes da norma, na verdade, são muitas vezes as poucas entradas para se investigar a complexidade de experiências de que não se têm outros registros. Por serem casos excepcionalmente ricos, são tomados como indícios raros de vivências cuja "normalidade" é impossível verificar. ${ }^{5}$ De qualquer forma, resta o desafio intrínseco ao método de se estabelecer o diálogo entre a realidade identificada no nível micro-histórico ("o vivido") e os processos macro-históricos nos quais essas vivências estão inseridas.

A historiografia da escravidão atlântica é um dos campos mais fecundos da historiografia contemporânea. Tendo partido, na primeira metade do século XX, da investigação acerca do funcionamento dos sistemas coloniais, o estudo da escravidão e do tráfico de escravos desenvolveu-se movido pelos interesses contemporâneos de compreender o funcionamento das relações sociais, a reiteração de hierarquias sociais, a construção de identidades e as interações entre as sociedades. Acompanhando as transformações metodológicas que permitem hoje tanto o processamento maciço de dados quantitativos quanto a reconstituição de redes de relações interpessoais e de trajetórias individuais a partir de séries documentais distintas, os historiadores da escravidão e do tráfico vêm respondendo aos desafios expostos por Sanjay Subrahmanyam, para outra área de estudos, de se trabalhar com "histórias conectadas" talvez antes mesmo desta proposta ter sido assim formulada. ${ }^{6}$ De fato, o trabalho de Pierre Verger ultrapassou pioneiramente os recortes nacionais convencionais e urdiu os dados levantados em um nível microscópico em três continentes para a análise das flutuaçôes do comércio e do fluxo de pessoas entre a Bahia e o Golfo de Benim, nos séculos XVII e XIX, regiōes separadas (e unidas) pelo Atlântico. ${ }^{7}$

Nas últimas duas décadas, o recurso ao uso de casos individuais ou à reconstituição de trajetórias individuais se tornou mais comum na historiografia da escravidão. As abordagens e objetivos diferem: alguns trabalhos abordam temas amplos a partir de histórias pessoais; outros organizam a narrativa em torno de um indivíduo; há também alguns ensaios biográficos. Vale citar alguns exemplos notáveis da historiografia da escravidão brasileira oitocentista. Visões da liberdade, de Sidney Chalhoub, tem por tema central os significados da liberdade nas últimas décadas da escravidão no Rio de Janeiro e os explora através de uma gama variada de fontes, de processos criminais e de açôes de liberdade a obras de literatura. O livro notabilizou-se por dar voz aos sujeitos escravizados e mostrá-los como agentes da história da abolição, antes contada apenas pela narrativa parlamentar. Mas, para alcançar essa outra perspectiva da história da abolição, Chalhoub precisou reunir os testemunhos de muitos escravos e escravas regis- 
trados nas ações de liberdade e em outros confrontos que chegavam aos tribunais, para então apurar os sentidos que davam à liberdade e as estratégias escolhidas diante da política de dominação dos senhores. Mesmo sem compor um coro orquestrado, essas vozes reunidas foram tomadas como indícios dos embates que resultaram na desintegração do domínio senhorial e, em última instância, na abolição. Silenciadas na versão construída pelos senhores, elas passaram a fazer parte da nova narrativa da abolição. ${ }^{8}$ Em $A$ conquista da liberdade, Regina Xavier fez uso intensivo de ações de liberdade e de testamentos de Campinas das últimas décadas da escravidão e dos anos subsequentes à abolição; neles identificou nominalmente homens e mulheres libertos que foram, em seguida, buscados em outros documentos, como registros cartoriais e licenças municipais. $\mathrm{O}$ cruzamento nominal permitiu reunir fragmentos dispersos das vidas de vários libertos e reconstituir suas estratégias na busca da alforria, suas relações sociais e suas opçōes de trabalho e moradia, demonstrando que agiram como protagonistas do processo de abolição, cada um a seu modo, seguindo variadas leituras da realidade. ${ }^{9}$ Já O fiador dos brasileiros é organizado em torno da trajetória de um indivíduo, Antônio Pereira Rebouças, para explorar os cruzamentos entre as lutas por direitos empreendidas pelos escravos e seus descendentes e os debates jurídicos acerca da definição de cidadania no Império. A trajetória excepcional normal do advogado mulato Rebouças serve de fio à narrativa tecida por Keila Grinberg a partir dos debates parlamentares, das açôes de liberdade e de outros processos da Corte de Apelação do Rio de Janeiro. A trama revela a atuação oscilante dos advogados e juízes na interpretação das leis, ora em defesa da propriedade, ora da liberdade. ${ }^{10}$ Já Domingos Sodré, um sacerdote africano é mais propriamente biográfico. Nele, João José Reis desafia a falta de testemunhos pessoais para reconstituir a história de um liberto africano que, vindo do Golfo do Benim, viveu quase toda sua vida na Bahia, onde se destacou como líder espiritual e temporal entre os africanos. O levantamento e o cruzamento de dados contidos em inventários, testamentos, registros cartoriais e eclesiásticos e, ainda, na documentação policial permitiram a Reis iluminar várias passagens da vida de Domingos e reconstituir seus círculos de relaçôes, mais notadamente a comunidade de africanos libertos em Salvador, gente que vivia muitas vezes à margem da lei, mas que soube achar espaços de sobrevivência e mesmo de prosperidade. Preenchendo os vazios com dados retirados do contexto reconstituído, Reis estendeu as fronteiras da reconstituição de trajetórias de escravos e libertos, sujeitos que pouquíssimos registros deixaram de próprio punho ou voz. ${ }^{11}$ De maneiras diversas, os trabalhos discutidos se utilizaram das histórias individuais não simplesmente para ilustrar contextos já conhecidos, mas para reconstruir contextos novos, em variações do exercício de redução da escala de análise análogo àquele proposto pela micro-história e discutido por Jacques Revel e primorosamente exemplificado no campo de estudos do pós-emancipação pelo livro mais recente de Rebecca Scott. ${ }^{12}$

\section{Os fragmentos deixados pelos sujeitos na era da abolição}

José e Francisco seguiram a bordo do Despatch para Trinidad em 1846, com um grupo grande de africanos emancipados do navio Flor de Luanda. ${ }^{13}$ Meu interesse pelos africanos do Flor de Luanda faz parte do que eu posso chamar de uma "prosopografia" do grupo de africanos livres no Brasil, que desenvolvi durante meu doutorado. Essa reconstituição da trajetória coletiva dos africanos emancipados dos navios condenados no âmbito da campanha contra o tráfico atlântico de escravos me fez transitar entre o micro e o macro e tirar, do conjunto das informações, conclusōes acerca dos significados da liberdade no Atlântico oitocentista, ao comparar a experiência dos africanos livres no Brasil às de outros grupos semelhantes em outras partes do Atlântico, e também do Índico. ${ }^{14}$ Para tal, utilizei uma gama de fontes encontradas em arquivos brasileiros: listagens nominais dos africanos emancipados dos navios condenados pela Comissão Mista Anglo-Brasileira entre 1830 e 1845; listagens daqueles emancipados pela Auditoria da Marinha nos anos 1850; registros de falecimento; listagens dos africanos a serviço das instituições públicas; correspondência expedida e recebida pela seção responsável pelos africanos livres no Ministério da Justiça, inclusive dos arrematantes particulares; petições de emancipação 
dos africanos livres ao fim do termo de serviço; e listas nominais compiladas pelo Ministério da Justiça na década de 1860 com os destinos de africanos livres de alguns carregamentos. ${ }^{15}$ Essa é uma das raras categorias cujos indivíduos podem ser acompanhados por tanto tempo. Algumas dessas pessoas podemos seguir por trinta anos. O tratamento qualitativo desse material permitiu traçar a experiência coletiva do grupo, entre a primeira emancipação, a fase de tutela e os arranjos de serviço junto a particulares e a instituições públicas, até o período da segunda emancipação, quando em petiçõos ao Imperador processadas pelo Ministério da Justiça os africanos livres relatavam suas trajetórias. Preocupei-me principalmente com as experiências de trabalho e com as margens de autonomia, que serviram de medida para a avaliação do significado da liberdade atribuída nos tratados bilaterais e na legislação de proibição do tráfico. A análise quantitativa das listagens da década de 1860 revelou com mais clareza a imagem de uma experiência muito distante daquela idealizada e inscrita na legislação, ao apontar para os longos termos de serviço e para a distinta experiência entre aqueles que serviram o Estado e aqueles que serviram a particulares. ${ }^{16}$

Só essa "descida" à trama, ao cotidiano do tratamento dos africanos livres pela administração imperial, daria acesso à experiência daqueles que sofreram os efeitos dos acordos relacionados à proibição do tráfico de escravos. Essas histórias de vida ficariam de outro modo absolutamente obscurecidas por leituras econômicas e diplomáticas dessa campanha. Por sua vez, o tratamento dispensado aos africanos livres revelado pela minha análise permitiu enxergar a interferência britânica na abolição do tráfico e a política imperial de uma nova perspectiva: a categoria dos africanos livres simbolizava o direito à liberdade, que devia ser estendido a todos os africanos importados desde a proibição do tráfico; e a pressão britânica servia de reforço a esse princípio, que ameaçava a escravidão na sua base, a legalidade. Assim, a categoria dos africanos livres deixou de ser vista apenas como um pequeno grupo de africanos que foi vítima do governo imperial pela exploração de seu trabalho compulsório e passou a pivô do embate diplomático anglo-brasileiro acerca da repressão do tráfico, tema central da história do Brasil oitocentista.

Ao investigar mais de perto as ações britânicas em defesa da liberdade dos africanos livres, reencontrei José e Francisco. Suas pistas estão na correspondência diplomática e, nesse caso, na correspondência entre a legação britânica no Rio de Janeiro e seus superiores no Ministério das Relações Exteriores britânico, em Londres. A série Foreign Office 84, em particular, reúne a correspondência recebida e expedida pelo setor "tráfico de escravos" do Ministério, fundado em 1819, que concentrava a comunicação com uma extensa rede de informantes baseados em todas as partes das Américas, África e Ásia. A riqueza dessa série documental é inestimável. Encontramos nela as discussões internas a respeito da negociação dos tratados bilaterais e as adaptações de sua aplicação, quando em vigor. Além disso, reúne a correspondência trocada entre os agentes remotos e Londres a respeito das atividades da Marinha Real na apreensão de navios e do funcionamento das comissões mistas e cortes do Almirantado, tribunais encarregados de julgar os navios apresados. E como se não bastasse, a documentação recebida pelo Ministério contém também relatórios sobre o volume e o funcionamento do tráfico de escravos, sobre o preço dos escravos e sobre assuntos locais relacionados à campanha de abolição, contidos em debates parlamentares e legislação. ${ }^{17}$ Como os ingleses criaram para si e alimentaram uma imagem de defensores das vítimas do tráfico de escravos, encontramos nessa documentação muitos casos de africanos que por vários caminhos caíram na rede de proteção do governo de Sua Majestade Britânica. Como já disse, o fato de José e Francisco, marinheiros do navio Dois de Fevereiro, apreendido em 1841, terem sido reclamados pelo senhor, Antônio Gonçalves da Luz, gerou correspondência entre a legação britânica no Rio de Janeiro e a Secretaria dos Negócios Estrangeiros do Império, e da mesma legação com seus superiores do Ministério, em Londres. Esses fragmentos, produzidos em circunstâncias especiais, são fundamentais para a reconstituição das trajetórias dos dois marinheiros, proposta aqui em três etapas: o diálogo com o contexto, a descida à trama e a volta ao contexto, para reescrevê-lo. 


\section{O diálogo com o contexto dado}

A partir dos documentos de que dispomos sobre José e Francisco, a primeira estratégia para reconstituir suas trajetórias implica dar significado aos pequenos fragmentos documentais disponíveis e preencher as lacunas com informaçôes retiradas do contexto. Em se tratando de indivíduos como eles, africanos trazidos pelo tráfico ou mesmo escravos nascidos nas Américas, que raramente deixaram testemunhos sobre si, esse procedimento permite construir a narrativa com base em informações possíveis e mesmo prováveis, pois baseadas na análise de conjuntos de indivíduos semelhantes, no mesmo lugar e tempo.

José Majojo e Francisco Moçambique eram escravos marinheiros de Antônio Gonçalves da Luz. Não está claro quando aportaram no Rio, vindos da longa rota com a Costa Oriental da África, mas Luz invoca um registro de pagamento de taxa de março de 1831 para provar sua propriedade sobre eles e também sua importação anterior à proibição do tráfico, se considerarmos a lei de 7 de novembro de 1831. Por esse documento, José Majojo e Francisco Moçambique seriam marinheiros do patacho Luz e teriam sido despachados para Porto Alegre, mediante o pagamento de $4 \$ 800$ réis por cada um. ${ }^{18}$ José e Francisco, ao que tudo indica, tinham sido transportados como escravos para o Brasil durante a fase em que a África Oriental passou a fazer parte das rotas dos comerciantes de escravos baseados na América portuguesa. Os "moçambiques" representaram em torno de um quinto dos escravos do Rio de Janeiro nas décadas que se seguiram à abertura dos portos. Um dos principais traços desse grupo era o desequilíbrio entre os sexos, com três homens para cada mulher e mortalidade muito alta. ${ }^{19}$ A demografia do tráfico fazia de José e Francisco sobreviventes do impacto microbiano e adultos com remotas chances de se casarem com mulheres de sua própria região de origem.

Sabemos, graças à transcrição de livros de impostos e passaportes de escravos remetidos do Rio de Janeiro para Minas Gerais e para o Sul, que Antônio Gonçalves da Luz era comerciante de escravos desde 1818, quando aparece despachando uma escrava ladina e um escravo novo para Campos, no Rio de Janeiro. ${ }^{20}$ Esses mesmos dados nos permitem reencontrar Antônio Gonçalves da Luz enviando para Campos dois escravos ladinos, em 1825, depois mais vinte escravos novos, em 1828, e outros dez escravos ladinos, em 1832, todos africanos. ${ }^{21}$ Nessa documentação, ele aparece também despachando duas escravas ladinas, Isabel e Maria, para Porto Alegre, em 1829. ${ }^{22}$ Não temos registro de sua nacionalidade ou idade, mas na remessa de 1832 os registros mostram que ele foi abonado por Antônio da Costa Souza Guimarães, que "vivia de negócios de atacado" e morava na rua de São Pedro, 106, na freguesia da Candelária, no Rio de Janeiro. Foi justamente na comunidade de comerciantes da Candelária que Gonçalves da Luz buscou testemunhas para provarem que José e Francisco eram seus escravos há tempos. Mesmo sem, por enquanto, ter outros dados sobre Gonçalves da Luz, podemos dizer que ele era ligado ao comércio de escravos, mantinha transações com o interior da província do Rio de Janeiro e com o Rio Grande do Sul, e talvez tivesse um patacho que fazia comércio com o Rio Grande, pois no documento anexado aos testemunhos, em 1841, José e Francisco foram declarados marinheiros a bordo do patacho Luz dez anos antes. Além disso, alguma ligação ainda não esclarecida Gonçalves da Luz tinha com o comércio de longa distância com a África, uma vez que foi como marinheiros na rota RioBenguela que os mesmos escravos foram apreendidos a bordo do Dois de Fevereiro no início de 1841.

Como marinheiros, José e Francisco faziam parte de uma categoria cuja principal característica era justamente sua diversidade. Africanos eram $17 \%$ das tripulações dos navios negreiros que abasteciam o mercado brasileiro entre o fim do século XVIII e o final do tráfico, em meados do XIX, convivendo com portugueses, outros europeus e brasileiros, além de asiáticos e outros latino-americanos. ${ }^{23}$ Entre os africanos, 8,9\% eram da Costa Oriental. Não sabemos suas posições na hierarquia de trabalho do navio, mas podemos com certeza discorrer sobre a dura vida a bordo e as doenças que se disseminavam facilmente entre os escravos debilitados nos porões e que ameaçavam contaminar a tripulação, que faziam de José e de Francisco, a cada vez, sobreviventes da travessia atlântica que tantos vitimava. A vida marítima proporcionava, sim, alguma mobilidade, contato com pessoas de origens e experiências diversas. Nisso, 
a experiência de José e de Francisco como escravos era muito distinta da de outros "moçambiques" presos às plantaçôes de café, cana, alimentos, ou daqueles que trabalhavam nas cidades. Não era à toa que os escravos que residiam nas regiōes litorâneas tinham os navios de passagem como alternativa de fuga. ${ }^{24}$

Desde que o tráfico de escravos começou a ser ameaçado pela campanha britânica, os comerciantes luso-brasileiros que controlavam o comércio do Atlântico Sul, havia mais de dois séculos, buscavam formas de se defender e de se manter em atividade. Daí resultou a dinamização da rota entre o Rio de Janeiro e Benguela, porto no sul de Angola onde se concentraram comerciantes luso-africanos envolvidos no comércio de cativos que buscavam escapar da vigilância mais intensa sobre o porto de Luanda. Buscavam também, segundo Mariana Cândido, diversificar suas exportaçôes, incluindo na pauta marfim, cera de abelha, resina e, mais tarde, borracha. ${ }^{25}$ Segundo os dados compilados no Transatlantic Slave Trade Database, Benguela respondeu, nos cinco primeiros anos da década de 1840, por 28\% de todos os escravos fornecidos para o Rio de Janeiro. Decaíam as exportaçôes por Luanda e cresciam as atividades nos portos de Cabinda e, na segunda metade da década, de Ambriz. ${ }^{26}$ Gonçalves da Luz talvez tivesse algum investimento no tráfico transatlântico, ou talvez apenas alugasse seus escravos para o capitão do navio. Por enquanto não sabemos. É certo, entretanto, que participava de negócio arriscado. Vigoravam o tratado anglo-português de 1815 e a convenção adicional de 1817 , além do alvará de 1818, que proibiam o uso da bandeira portuguesa para fornecer escravos para regiôes não portuguesas e previam pena de confisco do navio e da carga para os donos, além de degredo para os oficiais dos navios condenados. ${ }^{27}$ Vigorava o decreto de 10 de dezembro de 1836, de Sá da Bandeira, que proibia o tráfico no Império português. Vigorava também, desde 1839, o ato Palmerston, que igualava o tráfico em navios portugueses, ou sem bandeira, à pirataria e submetia os navios a julgamento em tribunais do Almirantado britânico. ${ }^{28}$ Do lado brasileiro, vigoravam o tratado anglo-brasileiro de 1826, que proibia a importação de escravos para o país e o envolvimento de súditos ou navios brasileiros no comércio de escravos, e a lei de 7 de novembro de 1831, que declarava livres todos os africanos que fossem importados a partir daquela data e incriminava todos os envolvidos com a importação de africanos, dos armadores e investidores à tripulação e compradores de escravos novos. ${ }^{29}$

Os comerciantes luso-brasileiros vinham se adaptando à proibição do tráfico de várias maneiras, o que conseguiam em colaboração com seus sócios estrangeiros e com a conivência das autoridades imperiais e de representantes diplomáticos de outros países. Faziam uso do expediente de manter dupla documentação no navio para o caso de serem abordados pelas autoridades encarregadas da repressão, faziam declaração falsa do destino do navio, assim como dos motivos de entrarem em lastro nos portos depois de terem desembarcado sua carga em praias mais afastadas. ${ }^{30} \mathrm{Da}$ mesma forma, a armação e o desembarque dos navios foram "descentralizados", isto é, levados para áreas em que o controle era menor ou podia ser corrompido. Algumas regiōes do litoral do Rio de Janeiro e de São Paulo, a baía de Paranaguá em particular e o litoral de Santa Catarina se tornaram, assim, bases para o tráfico ilegal ${ }^{31}$ Além disso, tornou-se mais comum a estratégia de separar a remessa de mercadorias para a costa da África do transporte do carregamento humano comprado em troca. Dessa forma, corria-se menos risco de apreensão e tornava-se o embarque na costa africana mais rápido, uma vez que os escravos ficavam reunidos em barracões só esperando a chegada do navio para a travessia. E estes eram cada vez mais modernos e ágeis. A eficiência na preparação da viagem se traduziu no significativo aumento do volume do tráfico ilegal, a despeito da proibição e da repressão. Tanto as estimativas quanto os dados confirmados do tráfico para o Brasil apontam que ele cresceu significativamente na década de 1840, atingindo picos antes não alcançados, e que o Sudeste se distanciou das outras regióes como o principal importadora. ${ }^{32}$

A historiografia sobre a repressão do tráfico brasileiro até menciona a apreensão de navios brasileiros e portugueses por cruzadores britânicos, mas nunca avançou na investigação do destino que lhes era dado. A apreensão e remessa do Dois de Fevereiro para Demerara, por exemplo, foi mencionada por Pierre Verger a partir da documentação britânica, no contexto da pressão sobre o tráfico brasileiro antes do ato Aberdeen (1845) e da formulação de uma política de recrutamento de mão de obra para as colônias bri- 
tânicas no Caribe, mas a informação para aí. ${ }^{33}$ A partir desse ponto, não há no contexto, na história conhecida da repressão do tráfico brasileiro, mais elementos que expliquem o destino de José e Francisco. Pouco se exploraram o tratamento dos marinheiros escravos apreendidos a bordo dos navios negreiros durante a campanha atlântica antitráfico e o impacto das perdas sofridas pelos traficantes brasileiros.

\section{A descida à trama}

A partir desse ponto, os fragmentos da trajetória de José e Francisco guiam-nos por áreas pouco exploradas ou mesmo não mapeadas da história da campanha antitráfico e da experiência africana na era da abolição. O trabalho é de seguir as pessoas, explorar mais de perto os fragmentos, para depois darlhes novos ou renovados sentidos. É uma tarefa descritiva, e o objetivo final está mais adiante.

A respeito do navio em que José e Francisco foram apreendidos, os registros do Ministério das Relaçôes Exteriores e do Almirantado britânicos detalham que o brigue Dois de Fevereiro partiu do Rio de Janeiro no fim de 1840 com destino a Benguela, onde carregou 500 pessoas, mais da metade delas crianças. O capitão Ezequiel Gomes da Silva e a tripulação de 18 pessoas da qual José e Francisco faziam parte conduziram o carregamento humano em uma travessia relativamente rápida, de 35 dias. O brigue ainda pôde desembarcar 195 cativos na costa do Rio de Janeiro antes de ser apreendido pela tripulação do cruzador britânico Fawn. Em vez de levá-lo a julgamento na comissão mista anglo-brasileira sediada no Rio de Janeiro, o comandante do Fawn optou por encaminhá-lo para julgamento na corte do Almirantado de Demerara. Até o destino final, no Caribe, faleceram 125 cativos, ou seja, um em cada quatro que haviam sido embarcados. Os restantes foram emancipados em Demerara e lá ficaram. ${ }^{34}$

Mas, antes de o Dois de Fevereiro seguir para o Caribe, no início de 1841, José e Francisco foram deixados a cargo do comandante da estação naval britânica no Rio. O caso rendeu longa negociação diplomática, na qual Antônio Gonçalves da Luz reclamava a restituição dos dois. Em novembro de 1841, o ministro brasileiro dos Negócios Estrangeiros, Aureliano de Souza e Oliveira Coutinho, encaminhou à legação britânica do Rio de Janeiro um requerimento de Gonçalves da Luz e pediu que o representante britânico procedesse a indagações sobre o aprisionamento dos dois escravos, demandando sua devolução. Hamilton respondeu prontamente admitindo a apreensão, mas negando a restituição dos escravos, por "não poder contrariar os acordos bilaterais". Acrescentou que pedidos semelhantes já haviam sido respondidos da mesma maneira pela legação britânica, e os motivos haviam sido expostos anteriormente, eximindo-se, assim, de detalhá-los naquela ocasião. ${ }^{35}$ No final de dezembro de 1841, Hamilton enviou esse relato a seu superior, Lorde Aberdeen. Seis meses depois, foi desautorizado.

Aureliano Coutinho buscou aconselhamento jurídico: o procurador da Coroa, Fazenda e Soberania Nacional reconheceu o zelo humanitário britânico, interpretou os acordos bilaterais e a legislação de repressão do tráfico e insistiu que o tratado bilateral não havia extinguido a escravidão e, portanto, não impedia "que cada um continuasse a possuir e a reputar de sua propriedade os [escravos] que já tinha e adquirisse até o prazo da abolição final do tráfico". ${ }^{36}$ Além disso, não dava o direito à Inglaterra de tornar libertos escravos legalmente possuídos. No ofício encaminhado a Hamilton, Aureliano complementou a argumentação do procurador da Coroa imperial com elaborado argumento político em defesa do direito à propriedade escrava no Brasil diante da campanha abolicionista britânica. $\mathrm{O}$ ministro expôs que tanto o tratado de 1826 quanto a lei de 1831 reconheciam a existência de escravos nas tripulações e determinavam que estes não fossem objeto das ações abolicionistas. Lembrava que as partes haviam concordado com tais determinaçôes quando negociaram e que

nem a intenção do Brasil nem a expressada em nome da Inglaterra nos respectivos tratados foi jamais a de confundir os escravos pretos (ainda mesmo que fossem encontrados a bordo de uma embarcação evidentemente empregada no tráfico) com os africanos arrancados do seu país natal depois da época da abolição daquele comércio. ${ }^{37}$ 
Aureliano demonstrava consciência e cuidado ao lidar com a linha tênue que distinguia o status das pessoas conforme circunstâncias cambiantes. Nesse caso, devia defender a liberdade dos africanos novos, mas também a propriedade dos traficantes brasileiros sobre os escravos marinheiros. Continuou ainda na linha tênue, em tom autoindulgente, argumentando que tratar seus súditos com justiça era dever do governo imperial

sempre que o fanatismo e um zelo pouco discreto ou um princípio especulativo que pode produzir as consequências mais funestas não haja desvairado os ânimos; dever que compele o Estado mais democrático dos tempos modernos a conservar a escravidão a par da mais ilimitada liberdade; dever que obrigou a Grã-Bretanha a sustentá-la até época mui recente apesar de distinguir-se esta nação há séculos do resto do universo pelas suas instituições liberais; e dever enfim que a par de tantas outras obrigações sociais é seguramente de natureza tal que às vezes aflige o coração humano mas que a sã política manda contudo cumprir sem hesitação e sem temer de censura, que será necessariamente injusta, enquanto os poderosos motivos sobre que se funda este dever continuarem a existir. ${ }^{38}$

Em termos velados, Aureliano se justificava pela defesa da escravidão, indicando que era circunstancial e justificada pela "sã política". Entretanto, os mesmos argumentos eram usados em outros momentos para justificar a conivência com a escravização ilegal dos africanos que haviam sido importados desde 1831, cuja liberdade era garantida pela lei e pelo tratado, como ele mesmo admitia.

Essa interpretação dos acordos bilaterais a respeito do status dos escravos marinheiros foi enviada para Londres e encaminhada por Aberdeen ao procurador-geral da rainha, que reconheceu que a convenção adicional de 1817 reconhecia a possibilidade de haver escravos marinheiros a bordo dos navios empregados no tráfico e determinava a emancipação apenas dos cativos destinados à venda. $\mathrm{O}$ procurador admitiu que nenhuma parte da convenção determinava a emancipação dos escravos membros da tripulação, nem estabelecia o modo como deveriam ser tratados, seja em comissões mistas sediadas em países estrangeiros, seja em colônias britânicas. ${ }^{39}$ Hamilton foi desautorizado, mas nem por isso voltou atrás. Nos meses seguintes reuniu informaçôes recentes sobre José e Francisco e soube que este último havia sido encaminhado ao Cabo da Boa Esperança como marinheiro de outro navio apreendido, o brigue Santo Antônio. Dizia-se que ele lá vivia como liberto. Já José estava a bordo do Crescent, o navio-hospital britânico fundeado no porto do Rio de Janeiro que servia de depósito dos africanos apreendidos nas investidas abolicionistas da Marinha britânica. Como José, havia vários que, segundo o comandante Donnelan, eram tratados como "landsmen", recrutas sem treinamento naval que recebiam salários e comida da Royal Navy, estando abaixo dos marujos. ${ }^{40}$ No caso de José e de Francisco, era como se entrassem novamente por baixo na hierarquia dos trabalhadores no mar. Mas outras coisas estavam em jogo. Segundo o comandante Donnelan, José se mostrou assustado com a perspectiva de ser devolvido a seu senhor, e seis de seus camaradas vieram em seguida interceder em favor dele e implorar que eles próprios não fossem também devolvidos, pois haviam se habituado a ver-se como livres, a receber pagamento e proteção da Inglaterra e a serem tratados como súditos britânicos, portanto não mais escravos. ${ }^{41}$ Aos olhos abolicionistas do comandante,

A prolongada residência destes negros a bordo do Crescent, o tratamento que têm experimentado e sua relação contínua com pessoas livres fez nascer neles o desejo natural pela Liberdade. O contraste dos seus passados com a condição presente neste período permitiu-lhes estimar com precisão o grande benefício que eles têm agora em jogo e não é nenhum exagero dizer que a angústia deles é tão grande quanto genuína. A apatia não é mais um traço do seu caráter, pois a consciência de serem tratados como homens inspirou suas mais nobres faculdades, eles ficaram industriosos, sua conduta geral boa, e a ideia de serem Ingleses é motivo de orgulho expresso abertamente. ${ }^{42}$

Para Donnelan e Hamilton, José e os outros africanos sob sua responsabilidade eram a amostra de como a liberdade era superior à escravidão e, ainda mais, de como os ingleses sabiam tratar os africanos. Garantir a liberdade deles era dar uma lição ao governo brasileiro; devolvê-los, um sinal de derrota. As- 
sim, o que Hamilton procurava negociar era que o governo britânico indenizasse Antônio Gonçalves da Luz por José e Francisco, para que eles não fossem devolvidos à escravidão. Foi o que agente britânico conseguiu em negociação com o senhor, mediada pelo secretário dos Negócios Estrangeiros, agora Honório Hermeto Carneiro Leão. Gonçalves da Luz teve que demonstrar que havia adquirido os dois legalmente e, para isso, apresentou dois recibos - mencionados anteriormente - de pagamento pelos direitos dos escravos José Majojo e Francisco Moçambique, que despachava para Porto Alegre como marinheiros do patacho Luz. Tendo provado que os escravos já eram seus e que estavam no Brasil antes da lei de proibição do tráfico, Gonçalves da Luz aceitou dar-lhes liberdade plena e incondicional mediante o recebimento de 1:600\$000 réis, não sem antes declarar seu receio de que estivessem "em estado menos feliz do que se achassem nesta capital tratados segundo usou sempre o suplicante, como filhos" ${ }^{43}$

Hamilton constatou junto aos negociantes locais que o valor pedido por Gonçalves da Luz correspondia ao valor de mercado para escravos marinheiros na praça do Rio de Janeiro. O senhor nem chegou a pedir indenização pelo valor dos serviços dos africanos entre a apreensão e a indenização; os salários de escravos marinheiros foram avaliados entre $16 \$ 000$ e $20 \$ 000$ réis mensais. ${ }^{44}$ Foi assim que o ministro de Estrangeiros, Ernesto Ferreira França, pôde incluir no relatório de sua pasta para o ano de 1844 a informação de que Antônio Gonçalves da Luz havia recebido da Grã-Bretanha indenização por seus escravos José e Francisco, do Dois de Fevereiro, ressaltando que reclamaçóes semelhantes a cargo da comissão mista de Londres não tinham tido o mesmo resultado. ${ }^{45}$ Infelizmente, o relatório não dá detalhes desses outros casos individuais, mas traz um panorama das dificuldades diplomáticas geradas pela campanha britânica de repressão ao tráfico: o ministro enumerou várias apreensões feitas a navios brasileiros em águas territoriais nacionais e apreensões em alto-mar em que os captores optaram por não levar as presas a julgamento na comissão mista, mas sim nos tribunais do Vice-Almirantado em Demerara e na colônia do Cabo da Boa Esperança. O ministro ressaltou que o governo imperial protestava sempre que os acordos internacionais ou o direito das gentes fossem violados em prejuízo dos súditos brasileiros. Traficantes e senhores de escravos, bem entendido.

A última notícia que temos de José e Francisco é de quando apareceram na lista de passageiros do Despatch. Nela foram registrados como José e Francisco Moçambique somente e como tendo sido da tripulação do Santo Antônio, junto com Jacob e Andrew (André) - estes, na verdade, eram do Maria Carlota e também haviam sido libertados mediante indenização a seus proprietários. Francisco aparece como casado com Tinga, uma africana parcialmente cega, provavelmente uma sequela de oftalmia contraída na travessia do Atlântico no Anna, navio apreendido em $1841 .{ }^{46} \mathrm{O}$ maior grupo de passageiros do Despatch era de malungos do Flor de Luanda, navio português apreendido em 1838, cujo julgamento na comissão mista do Rio demorou e se complicou. Por isso, o encarregado de negócios britânico à época, William Gore Ouseley, pôs os africanos sob tutela da Santa Casa de Misericórdia e de particulares de sua confiança por oito anos. Cumprido o tempo, os 105 sobreviventes receberam cartas de emancipação definitivas e pagamento pelos anos de serviço compulsório, além de ter a opção de ficar no Brasil ou de ir para uma colônia britânica, onde "gozariam da plena liberdade". Aceitaram os que tinham família: no Despatch embarcaram 28 africanos livres do Flor de Luanda com 7 crianças e 14 africanos de vários carregamentos que haviam servido no Crescent mais 3 crianças. Eram 52 pessoas no total, que chegaram a Trinidad em fevereiro ou março de 1847 e começaram vida nova. Não sabemos se foram postos sob contrato como os outros africanos livres que para lá eram levados diretamente dos tribunais de Vice-Almirantado. ${ }^{47}$ Como nas colônias britânicas os africanos livres não eram alvo de obsessivo controle das autoridades coloniais, perdemos José e Francisco em Trinidad em 1847, sem saber se ficaram por lá ou se seguiram viagem. ${ }^{48}$ 


\section{Reescrevendo o contexto e extraindo significados das trajetórias}

Esses fragmentos reunidos na documentação diplomática britânica sobre José Majojo e Francisco Moçambique revelam trajetórias muito ricas e próprias da era da abolição, época de embates acerca dos significados da liberdade, de novos fluxos migratórios através do Atlântico e de novas fronteiras entre solo livre e solo escravo. Entretanto, se ficássemos apenas na descrição de suas trajetórias, contaríamos uma boa história e somaríamos dois nomes à lista de indivíduos resgatados do anonimato, deixando o trabalho de historiador incompleto. Os significados de suas trajetórias vão além das duas histórias individuais: iluminam novos contextos até agora pouco explorados na historiografia brasileira e atlântica e ajudam a repensar antigos. Vou apontar aqui cinco dos caminhos possíveis de interpretação desses fragmentos.

O primeiro diz respeito ao recrutamento de africanos para trabalhar nas colônias britânicas no Caribe. Quando o Dois de Fevereiro foi capturado, em 1841, em vez de ser levado à comissão mista sediada no Rio de Janeiro, foi julgado na corte do Vice-Almirantado britânico na Guiana. Estava tomando forma a nova política do abolicionismo britânico, que conjugava os esforços da Marinha Real na repressão ao tráfico ao atendimento da demanda por mão de obra nas colônias, onde a escravidão já tinha sido abolida e se implantava trabalho por contrato. Tratado na literatura anglo-saxônica como um esquema de recrutamento de africanos, encaminhou número significativo de africanos recapturados dos navios negreiros para as colônias até o início da década de 1860, mas teve seu auge justamente entre 1845 e 1850, quando o tratado anglo-brasileiro deixou de vigorar, e a Grã-Bretanha instituiu o ato Aberdeen, que declarava o tráfico brasileiro pirataria e determinava que os navios apreendidos fossem julgados em cortes do Almirantado britânicas. Das cortes mais procuradas pelos comandantes da Marinha Real britânica para julgar os navios em rota para o Brasil e para Cuba, Serra Leoa ou Santa Helena, os africanos encontrados a bordo nos navios negreiros eram reencaminhados para colônias britânicas, onde eram postos sob contrato de trabalho de tempo fixo (indentures). $\mathrm{O}$ esquema de recrutamento de africanos forneceu mão de obra muito necessária, enquanto o recrutamento de indianos e chineses para as colônias britânicas estava ainda no começo. ${ }^{49} \mathrm{O}$ que a história de José e Francisco nos aponta é a existência do ramo Rio de Janeiro-Caribe britânico desse esquema, iluminando um pouco seu funcionamento. Em artigo recente, discuti as formas de recrutamento adotadas pelos agentes britânicos nesse ramo do esquema, mostrando que, embora o número maior dos "emigrantes" partindo do Rio fosse dos africanos cuja travessia atlântica era interrompida pela captura dos navios que os transportavam, também caíram na malha africanos livres (como os do Flor de Luanda), marinheiros, escravos fugitivos e escravos sendo transportados no comércio interprovincial de cabotagem..$^{50}$

A descoberta do ramo brasileiro de recrutamento de trabalhadores africanos para as colônias britânicas sugere que a fase da campanha abolicionista britânica a partir de 1840 merece um novo olhar da historiografia brasileira dedicada ao tema da abolição do tráfico de escravos. Esse é o segundo caminho que eu gostaria de apontar. Ainda que os principais trabalhos tenham discutido o impacto do ato Aberdeen sobre as relações diplomáticas entre a Grã-Bretanha e o Brasil e demonstrado o aumento de apreensões de navios brasileiros, inclusive em águas territoriais brasileiras, não houve ainda uma quantificação dessas apreensões de navios nem consideração sobre o fato de que transferiam para o Caribe mão de obra destinada ao Brasil. Sobretudo, caberia uma discussão minuciosa do impacto que as apreensões tiveram sobre a diplomacia e sobre a política brasileiras, pois iam além de perdas monetárias dos traficantes. A documentação oficial brasileira sugere que talvez o próprio governo brasileiro evitasse dar muita publicidade à questão. No relatório do ministro de Estrangeiros em 1846, há anexa uma listagem dos casos julgados pela comissão mista do Rio de Janeiro, mas não há uma para a de Serra Leoa. Só em 1849 aparece no relatório de estrangeiros uma compilação dos casos de navios brasileiros julgados por cortes do Vice-Almirantado britânico. ${ }^{51}$ A seção de Estrangeiros do Conselho de Estado vinha lidando com vários casos espinhosos de interpretação do acordo bilateral assinado em 1826 e de apreensões de navios à revelia desse acordo. Isso ocorria ao mesmo tempo que o Ministério de Estrangeiros mediava uma varie- 
dade de casos, alguns como o pedido de restituição de José e Francisco feito por Gonçalves da Luz. Desde a Independência, a diplomacia brasileira se formava e amadurecia nas negociações com a Inglaterra a respeito do comércio e da proibição do tráfico de escravos. Foi notável, por exemplo, sua capacidade para defender o tráfico em nome da proteção dos interesses brasileiros e da aplicação estrita dos acordos bilaterais no julgamento dos navios. É plausível sugerir que as medidas adotadas pela Grã-Bretanha nessa nova fase da campanha abolicionista tenham posto a autoridade dos estadistas brasileiros perante sua base de apoio à prova, pois escaparam unilateralmente dos acordos bilaterais e impuseram consequências que fugiam ao controle brasileiro. As decisões tomadas pelo governo brasileiro reprimindo o tráfico a partir de 1850 podem ser reinterpretadas a partir dessa nova leitura da campanha britânica.

Um terceiro campo de pesquisa iluminado pela trajetória de José e Francisco é o do tratamento dos marinheiros, em particular os escravos, pela legislação e pelos tribunais de julgamento dos navios envolvidos no tráfico atlântico. Não há estudo monográfico sobre o tema, e as fontes sugerem sua complexidade. ${ }^{52}$ Enquanto os acordos bilaterais não determinavam o destino dos marinheiros escravos e remetiam a punição da tripulação para a legislação de cada país, na prática alguns escravos da tripulação de navios condenados por tráfico ilegal foram emancipados junto com a carga. Foi aparentemente o caso, por exemplo, dos quatro marinheiros do Orion, registrados apenas como "ladinos" e emancipados com os "boçais", em 1836. Resta saber se foram tratados como africanos livres. ${ }^{53}$ Segundo Jenny Martinez, a interpretação dada pelas autoridades britânicas nas comissões mistas era a de que a tripulação escrava dos navios devia ser entregue às autoridades de seu país de nacionalidade para julgamento. ${ }^{54}$ Mas claramente não foi isso que aconteceu com José e Francisco. Suas histórias apontam para uma transição na política britânica com relação aos escravos que caíam sob seu domínio, que ainda seria radicalizada em 1850 e 1851.

O quarto caminho para o qual a trajetória de José e Francisco aponta parte justamente da defesa que os agentes britânicos faziam da liberdade dos africanos. Ela começou com os africanos emancipados pela comissão mista, cuja tutela lhes interessava de perto, passou pelos marinheiros escravos e outros fugitivos que buscavam sua proteção e, por fim, incluiu todos os africanos que tivessem sido importados depois da proibição do tráfico (1830-31), o que equivalia a defender a abolição imediata da escravidão. Essa ampliação da definição de "africano livre" por parte dos agentes britânicos chegou ao público por meio das notícias da repressão ao tráfico e por outros meios menos abertos, e também chegou aos africanos livres e aos escravos. ${ }^{55}$ Valeria explorar o entendimento que os africanos tinham desse conflito diplomático e o uso que faziam dele. Por fim, caberia também se perguntar que impacto a posição britânica mais radical teve sobre as estratégias de domínio senhorial e a política do governo imperial de manutenção da escravidão ao longo do século XIX.

Mais um caminho se abre se pensarmos que a situação de José e Francisco era também a de tantos outros africanos e crioulos que viviam em condições ambíguas criadas justamente pelas situações postas pela abolição do tráfico de escravos e pela redefinição de fronteiras entre a escravidão e a liberdade. Os africanos livres que viviam sob tutela, os africanos importados ilegalmente que eram mantidos como escravos, os libertos ou pessoas de cor livres que estavam constantemente ameaçados de reescravização, os escravos que viviam em territórios em fase de abolição, os filhos de africanas livres ou de escravas alforriadas, condicionalmente, eram todos sujeitos que viviam, tanto quanto José e Francisco, a ambiguidade de seu status jurídico e a incerteza de não ter garantia da liberdade. As condições ambíguas não foram novidade da era da abolição, mas nela certamente se multiplicaram, alimentadas pelos processos de abolição do tráfico e da escravidão em muitos territórios atlânticos e pela manutenção da escravidão em outros, onde circulavam ideias e se reproduziam estratégias abolicionistas, especialmente onde os próprios sujeitos usavam-nas para abrir brechas na dominação escravista.

O caso de José Majojo e Francisco Moçambique serviu aqui como exercício de reflexão a respeito da reconstituição de trajetórias individuais da era da abolição e de exposição e discussão do uso da documentação disponível e das várias abordagens possíveis para a discussão dos casos individuais em seus contextos. Os limites da escrita biográfica de sujeitos que não deixaram seus próprios registros não im- 
José Majojo e Francisco Moçambique, marinheiros das rotas atlânticas: NOTAS SOBRE A RECONSTITUIÇÃO DE TRAJETÓRIAS DA ERA DA ABOLIÇÃo

Beatriz Gallotti Mamigonian

pedem os historiadores da escravidão atlântica de explorar por meio de registros indiretos e fragmentados o protagonismo dos atores sociais e os múltiplos significados de suas trajetórias complexas, vividas em um tempo de mudança, muita incerteza, mas também de expectativas nos novos sentidos da liberdade e da cidadania.

\section{Notas}

${ }^{1}$ Lista anexa a Hudson para Palmerston, 15/12/1846, National Archives of Great Britain, Foreign Office 84 (Slave Trade)/634 (a partir de agora citada como FO 84); Hamilton para Aberdeen, 24/12/1841, FO 84/1433; Hamilton para Aberdeen, 22/06/1843, FO 84/1433.

${ }^{2}$ Para uma perspectiva um pouco distinta do problema, ver LEVI, Giovanni. Usos da biografia. In: FERREIRA, Marieta de Moraes; AMADO, Janaína (Orgs.). Usos e abusos da história oral. Rio de Janeiro: Ed. da FGV, 1996, p. 167-191.

${ }^{3}$ GINZBURG, Carlo. O queijo e os vermes: o cotidiano e as ideias de um moleiro perseguido pela Inquisição. São Paulo: Companhia das Letras, 1989.

${ }^{4}$ CORBIN, Alain. Le monde retrouvé de Louis-François Pinagot: sur les traces d'un inconnu. Paris: Flammarion, 1998.

${ }^{5}$ GINZBURG, Carlo. O nome e o como: troca desigual e mercado historiográfico. In: GINZBURG, Carlo (Org.). $A$ micro-história e outros ensaios. Rio de Janeiro: Bertrand Brasil/DIFEL, 1989, p. 169-178.

${ }^{6}$ SUBRAHMANYAM, Sanjay. Connected histories: notes towards a reconfiguration of early-Modern Eurasia. Modern Asian Studies, v. 31, no 3, p. 735-762, 1997.

${ }^{7}$ VERGER, Pierre. Fluxo e refluxo do tráfico de escravos entre o golfo do Benin e a Bahia de Todos os Santos dos séculos XVII a XIX. São Paulo: Corrupio, 1987. (Ed. original Haia e Paris: Mouton, 1968).

${ }^{8}$ CHALHOUB, Sidney. Visões da liberdade: as últimas décadas da escravidão na Corte. São Paulo: Companhia das Letras, 1990.

${ }^{9}$ XAVIER, Regina C. L. A conquista da liberdade: libertos em Campinas na segunda metade do século XIX. Campinas: Centro de Memória da Unicamp, 1996.

${ }^{10}$ GRINBERG, Keila. O fiador dos brasileiros: cidadania, escravidão e direito civil no tempo de Antônio Pereira Rebouças. Rio de Janeiro: Civilização Brasileira, 2002.

${ }^{11}$ REIS, João José. Domingos Sodré, um sacerdote africano: escravidão, liberdade e candomblé na Bahia do século XIX. São Paulo: Companhia das Letras, 2008.

${ }^{12}$ REVEL, Jacques, Microanálise e construção do social. In: REVEL, Jacques (Org.). Jogos de escalas: a experiência da microanálise. Rio de Janeiro: Ed. da FGV, 1998, p. 15-38; SCOTT, Rebecca J. Degrees of freedom: Louisiana and Cuba after slavery. Cambridge, MA: Belknap Press of Harvard University Press, 2005.

${ }^{13}$ Lista anexa a Hudson para Palmerston, 15/12/1846, FO 84/634.

${ }^{14}$ MAMIGONIAN, Beatriz G. To be a liberated African in Brazil: labour and citizenship in the nineteenth century. Tese de Doutorado apresentada ao Programa de Pós-Graduação em História da University of Waterloo. Waterloo, Canadá, 2002.

${ }^{15}$ Os principais maços e códices utilizados foram: Arquivo Nacional (AN) IJ6 467 Africanos - Cartas de libertação e mapas de falecimento, 1831-1863; AN IJ6 468 Ofícios do Chefe de Polícia e Casa de Correção sobre africanos, 1834-1864; AN IJ6 469 Ofícios de diversas autoridades sobre africanos, 1824-1864; AN IJ6 471 Ofícios, relações e processos sobre africanos livres, 1834-1864; AN IJ6 523, Ofícios e processos sobre africanos livres, 1833-1864; AN IJ6 524, Africanos - Cartas de libertação, 1845-1864; AN IJ6 15, Tráfico de Africanos - Registro de avisos a diversas autoridades, 4aa seção, 1859-1862; AN IJ6 16, Africanos livres - Registro de avisos a diversas autoridades, 1863-1865.

${ }^{16}$ MAMIGONIAN, Beatriz G. Revisitando o problema da "transição para o trabalho livre": a experiência dos africanos livres. In: FLORENTINO, Manolo (Org.). Tráfico, cativeiro e liberdade (Rio de Janeiro, séculos XVII-XIX). Rio de Janeiro: Civilização Brasileira, 2005, p. 389-417; MAMIGONIAN, Beatriz G. A harsh and gloomy fate: liberated Africans in the service of the Brazilian state, 1830s 1860s. In: CURRY, Dawne Y.; DUKE, Eric D.; SMITH, Marshanda (Orgs.). Extending the diaspora: new scholarship on the history of black peoples. Champaign, IL: University of Illinois Press, 2009, p. $24-45$.

${ }^{17}$ Sobre documentação da campanha britânica de abolição do tráfico ver em particular BETHELL, Leslie. The mixed commissions for the suppression of the transatlantic slave trade in the nineteenth century. In: Journal of African History v. 7, no 1 , p. 79-93, 1966. Ver também ELTIS, David. Economic growth and the ending of the transatlantic slave trade. Oxford: Oxford University Press, 1987; MARTINEZ, Jenny S. Antislavery courts and the Dawn of International Human Rights Law. In: Yale Law Journal, no 117, p. 550-641, 2008.

${ }^{18}$ Atestado emitido pela Contadoria da Intendência Geral da Polícia do Rio de Janeiro a partir do Livro Primeiro de lançamento de direitos de escravos para os portos do sul, para José Majojo e igual para Francisco Moçambique, cópia anexa a Hamilton para Aberdeen, 22/06/1843, ST 17, FO 84/1433. 
José Majojo e Francisco Moçambique, marinheiros das rotas atlânticas: NOTAS SOBRE A RECONSTITUIÇÃO DE TRAJETÓRIAS DA ERA DA ABOLIÇÃO

Beatriz Gallotti Mamigonian

${ }^{19}$ FLORENTINO, Manolo. Aspectos sociodemográficos da presença dos escravos moçambicanos no Rio de Janeiro, c.1790-c.1850. In: FRAGOSO, João; FLORENTINO, Manolo; SAMPAIO, Antonio Carlos Jucá; CAMPOS, Adriana Pereira (Orgs.). Nas rotas do império: eixos mercantis, tráfico e relaçốes sociais no mundo português. Vitória: Edufes; Lisboa: Instituto de Investigações Científicas e Tropicais; Brasília: CNPq, 2006, p. 193-244; KARASCH, Mary. A vida dos escravos no Rio de Janeiro (1800-1850). São Paulo: Companhia das Letras, 2000; ALPERS, Edward A. "Mozambiques" in Brazil: another dimension of the African diaspora in the Atlantic world. In: CURTO, José C.; SOULODRE-LA FRANCE, Renée (Eds.). Africa and the Americas: interconnections during the slave trade. Trenton, NJ: Africa World Press, 2005, p. 43-68; ROCHA, Aurélio. Contribuições para o estudo das relações entre Moçambique e o Brasil - século XIX: tráfico de escravos, relaçôes políticas e culturais. STVDIA, Lisboa, no 51, p. 61-118, 1992.

${ }^{20}$ AN, Cód. 421, v. 10, 28/04/1818, 123 v. Esses dados vêm do trabalho empreendido pela equipe coordenada por João Fragoso e Roberto Guedes Ferreira, Tráfico de Escravos, Mercadores e Fianças: Dois Bancos de Dados (despachos de escravos, passaportes e licenças). Brasília: IPEA, 2001.

${ }^{21}$ AN, Cód. 425, v. 1, 11/02/1825, 278; AN, Cód. 425, v. 2, 26/09/1828, 265; AN, Cód. 411, v. 15, 07/05/1832, 172, remessa também registrada em Cód. 424, v. 8, 73 e Cód 425, v. 4, 109.

${ }^{22}$ AN, Cód. 424, v. 3, 17/06/1829, fl. 8, verso.

${ }^{23}$ RODRIGUES, Jaime. De costa a costa: escravos, marinheiros e intermediários do tráfico negreiro de Angola ao Rio de Janeiro (1780-1860). São Paulo: Companhia das Letras, 2005, p. 186-187.

${ }^{24}$ SOARES, Carlos Eugênio Líbano. A capoeira escrava e outras tradiçôes rebeldes no Rio de Janeiro, 1808-1850. Campinas: Ed. da Unicamp; Centro de Pesquisa em História Social da Cultura, 2001; REBELATTO, Martha. Uma saída pelo mar: rotas de fuga escrava em Santa Catarina no século XIX. In: Revista de Ciências Humanas, Florianópolis, no 40, p. 423-442, 2006.

${ }^{25}$ CÂNDIDO, Mariana Pinho. Enslaving frontiers: slavery, trade, and identity in Benguela (1780-1850). Tese de Doutorado apresentada ao Programa de Pós-Graduação em História da York University. Toronto, Canadá, 2006, p. 111-112.

${ }^{26}$ Ver viagens partindo do Rio de Janeiro entre 1831 e 1850 em ELTIS et alii. Transatlantic Slave Trade Database Online, www.slavevoyages.org.

${ }^{27}$ Carta de Lei de 8 de novembro de 1817. Ratifica a Convenção Adicional ao Tratado de 22 de janeiro de 1815 entre este Reino e o da Grã-Bretanha assinada em Londres em 22 de julho deste ano sobre o comércio ilícito da escravatura. In: Coleção das Leis do Brasil, 1816-1817, Rio de Janeiro: Imprensa Nacional, 1890, p. 74-101; Alvará com força de lei de 26 de janeiro de 1818. In: Coleção das leis do Brasil de 1818. Rio de Janeiro: Imprensa Nacional, 1889, p. 7-10.

${ }^{28}$ Grã-Bretanha, $2 \& 3$ VIC cap. 73. "An Act for the Suppression of the Slave Trade”. Ver BETHELL, Leslie. Britain, Portugal and the suppression of the Brazilian slave trade: the origins of Lord Palmerston's Act of 1839. English Historical Review, v. 80, no 4, p. 761-784, 1965.

${ }^{29}$ Carta de Lei de 23 de novembro de 1826. Ratifica a Convenção entre o Império do Brasil e a Grã-Bretanha para a Abolição do Tráfico de Escravos, In: Coleção das Leis do Império do Brasil, Parte II - Atos do Poder Executivo, 1826. Rio de Janeiro: Typographia Nacional, 1880, p. 71-75; Lei de 7 de novembro de 1831. In: Coleção de Leis do Império do Brasil, 1831. Rio de Janeiro: Typographia Nacional, 1875, p. 182-184.

${ }^{30}$ VERGER. Fluxo e refluxo; BETHELL, Leslie. A abolição do tráfico de escravos no Brasil. Rio de Janeiro: Expressão e Cultura; São Paulo: Edusp, 1976; CONRAD, Robert E. World of sorrow: the African slave trade to Brazil. Baton Rouge: Louisiana University Press, 1986; TAVARES, Luís Henrique Dias. Comércio proibido de escravos. São Paulo: Ática, 1988; RODRIGUES, Jaime. O infame comércio: propostas e experiências no final do tráfico de escravos, 1800-1850. Campinas: Ed. da Unicamp; CECULT, 2000.

${ }^{31}$ CANABRAVA, Alice P. Um desembarque clandestino de escravos em Cananeia. Revista de História, v. 1, no 1, p. 559-562, 1950; BOCCIA, Ana Maria Mathias; MALERBI, Eneida Maria. O Contrabando de Escravos para São Paulo. Revista de História 56, no 112, p. 321-79, 1977; ABREU, Martha. O caso do Bracuhy. In: CASTRO, Hebe Mattos de; SCHNOOR, Eduardo (Orgs.). Resgate: uma janela para o oitocentos. Rio de Janeiro: Topbooks, 1995, p. 165-195; LEANDRO, José Augusto. Em águas turvas: navios negreiros na baía de Paranaguá. Esboços, Florianópolis, no 10, p. 99-117, 2003; ALONSO, Priscila Lima. O vale do nefando comércio: o contrabando de escravos no Vale do Pará́ba paulista entre 1850-1860. Dissertação de Mestrado em História Social apresentada à Universidade de São Paulo. São Paulo, 2006.

32 ELTIS et alii. Transatlantic Slave Trade Database Online.

${ }^{33}$ VERGER. Fluxo e refluxo, p. 375-376.

${ }^{34}$ ELTIS et alii. Transatlantic Slave Trade Database Online, voyage ID 2105 (Dois de Fevereiro).

${ }^{35}$ Hamilton para Aberdeen, 24/12/1841, FO 84/1433, contendo anexos: Aureliano de Souza e Oliveira Coutinho para Hamilton, 05/11/1841 e Hamilton para Aureliano Coutinho, 10/11/1841.

${ }^{36}$ Aureliano Coutinho para Hamilton, 24/01/1842, anexada a Hamilton para Aberdeen, 22/02/1842, FO 84/1433.

${ }^{37}$ Idem. 
José Majojo e Francisco Moçambique, marinheiros das rotas atlânticas: NOTAS SOBRE A RECONSTITUIÇÃO DE TRAJETÓRIAS DA ERA DA ABOLIÇÃo

Beatriz Gallotti Mamigonian

${ }^{38}$ Idem.

${ }^{39}$ Aberdeen para Hamilton, 03/06/1842, FO 84/1433.

${ }^{40}$ Hamilton para Aberdeen, 20/09/1842, FO 84/1433; Verbete "landsmen" em The Oxford Companion to Ships and the Sea. Oxford: Oxford University Press, 2006, consultado em Encyclopedia.com. (Acesso 11/10/2009). http://www.encyclopedia.com/doc/1O225-landsmen.html.

${ }^{41}$ Donnelan para Hamilton, 06/08/1842, anexo a Hamilton para Aberdeen, 20/09/1842, FO 84/1433.

${ }^{42}$ Idem.

${ }^{43}$ Nota de Antônio Gonçalves da Luz para a Secretaria dos Negócios Estrangeiros, 26/04/1843, anexa a Hamilton para Aberdeen, 22/06/1843, FO 84/1433.

${ }^{44}$ Hamilton para Aberdeen, 22/06/1843, FO 84/1433.

${ }^{45}$ BRASIL. Relatório da Repartição dos Negócios Estrangeiros apresentado a 13 de janeiro de 1845 pelo Ministro e Secretário de Estado Ernesto Ferreira França. Rio de Janeiro: Typographia Laemmert, 1845, p. 25-26.

${ }^{46}$ Hudson para Palmerston, 15/12/1846, FO 84/634.

${ }^{47}$ Ver MAMIGONIAN, Beatriz G. In the name of freedom: slave trade abolition, the law and the Brazilian branch of the African emigration scheme (Brazil-British West Indies, 1830s-1850s). In: Slavery \& Abolition, v. 30, no 1, p. 41-66, 2009.

${ }^{48}$ Sobre os "liberated Africans" em Trinidad, ver ADDERLEY, Rosanne Marion. New Negroes from Africa: slave trade abolition and free African settlement in the nineteenth-century Caribbean. Bloomington: Indiana University Press, 2006.

${ }^{49}$ ASIEGBU, J. U. J. Slavery and the politics of liberation, 1787-1861: a study of liberated African emigration and British anti-slavery policy. New York: Africana Publishing Corp, 1969; LOOK LAI, Walton. Indentured labor, Caribbean sugar: Chinese and Indian migrants to the British West Indies, 1838-1918. Baltimore: Johns Hopkins University Press, 1993; SCHULER, Monica. "Alas, Alas, Kongo": a social history of indentured African immigration into Jamaica, 1841-1865. Baltimore: The Johns Hopkins University Press, 1980; SCHULER, Monica. Liberated Central Africans in nineteenth-century Guiana. In: HEYWOOD, Linda M. (Org.) Central Africans and cultural transformations in the American diaspora. Cambridge: Cambridge University Press, 2002, p. 319-352.

${ }^{50}$ MAMIGONIAN. In the name of freedom... Op. cit.

${ }^{51}$ BRASIL. Relatório da Repartição dos Negócios Estrangeiros apresentado à Assembleia Geral Legislativa na quarta sessão da sexta legislatura pelo respectivo ministro e secretário de Estado Barão de Cairu. Rio de Janeiro: Typographia Imperial e Constitucional de Villeneuve, 1847, p. 17-24; BRASIL. Relatório da Repartição dos Negócios Estrangeiros apresentado à Assembleia Geral Legislativa na primeira sessão da oitava legislatura pelo respectivo ministro e secretário de Estado Paulino José Soares de Souza. Rio de Janeiro: Typographia Imperial e Constitucional de Villeneuve, 1850, anexos 146 a 149.

$52 \mathrm{O}$ que chega mais perto é o de Emma Christopher, mas vai apenas até a proibição do tráfico pela Grã-Bretanha: CHRISTOPHER, Emma. Slave ship sailors and their captive cargoes (1730-1807). New York: Cambridge University Press, 2006.

${ }^{53}$ AN, Códice 184, v. 3.

${ }^{54}$ MARTINEZ. Op. cit., p. 591-592.

${ }^{5}$ MAMIGONIAN, Beatriz. A Grã-Bretanha, o Brasil e as "complicações no estado atual da nossa população": revisitando a abolição do tráfico atlântico de escravos (1848-1851). Comunicação apresentada no IV Encontro Escravidão e Liberdade no Brasil Meridional. Curitiba, 2009.

\section{Referências bibliográficas}

ABREU, Martha. O caso do Bracuhy. In: CASTRO, Hebe Mattos de; SCHNOOR, Eduardo (Orgs.). Resgate: uma janela para o oitocentos. Rio de Janeiro: Topbooks, 1995, p. 165-195.

ADDERLEY, Rosanne Marion. New Negroes from Africa: slave trade abolition and free African settlement in the nineteenth-century Caribbean. Bloomington: Indiana University Press, 2006.

ALONSO, Priscila Lima. O vale do nefando comércio: o contrabando de escravos no Vale do Paraíba Paulista entre 18501860. Dissertação de Mestrado em História Social apresentada à Universidade de São Paulo. São Paulo, 2006.

ALPERS, Edward A. "Mozambiques" in Brazil: another dimension of the African diaspora in the Atlantic world. In: CURTO, José C.; SOULODRE-LA FRANCE, Renée (Eds.). Africa and the Americas: interconnections during the slave trade. Trenton, NJ: Africa World Press, 2005, p. 43-68.

ASIEGBU, J. U. J. Slavery and the politics of liberation, 1787-1861: a study of liberated African emigration and British anti-slavery policy. New York: Africana Publishing Corp, 1969. 
BETHELL, Leslie. A abolição do tráfico de escravos no Brasil. Rio de Janeiro: Expressão e Cultura; São Paulo: Edusp, 1976.

. Britain, Portugal and the suppression of the Brazilian slave trade: the origins of Lord Palmerston's Act of 1839. English Historical Review, v. 80, no 4, p. 761-784, 1965.

. The mixed commissions for the suppression of the transatlantic slave trade in the nineteenth century. Journal of African History, v. 7, no 1, p. 79-93, 1966.

BOCCIA, Ana Maria Mathias; MALERBI, Eneida Maria. O contrabando de escravos para São Paulo. Revista de História, v. 56, no 112, p. 321-379, 1977.

BRASIL. Relatório da Repartição dos Negócios Estrangeiros apresentado a 13 de janeiro de 1845 pelo Ministro e Secretário de Estado Ernesto Ferreira França. Rio de Janeiro: Typographia Laemmert, 1845.

BRASIL. Relatório da Repartição dos Negócios Estrangeiros apresentado à Assembleia Geral Legislativa na quarta sessão da sexta legislatura pelo respectivo ministro e secretário de Estado Barão de Cairu. Rio de Janeiro: Typographia Imperial e Constitucional de Villeneuve, 1847.

BRASIL. Relatório da Repartição dos Negócios Estrangeiros apresentado à Assembleia Geral Legislativa na primeira sessão da oitava legislatura pelo respectivo ministro e secretário de Estado Paulino José Soares de Souza. Rio de Janeiro: Typographia Imperial e Constitucional de Villeneuve, 1850.

BRASIL. Coleção de Leis do Império do Brasil, 1831. Rio de Janeiro: Typographia Nacional, 1875.

BRASIL. Coleção das Leis do Império do Brasil. Parte II - Atos do Poder Executivo, 1826. Rio de Janeiro: Typographia Nacional, 1880.

BRASIL. Coleção das Leis do Brasil de 1818. Rio de Janeiro: Imprensa Nacional, 1889.

BRASIL. Coleção das Leis do Brasil, 1816-1817, Rio de Janeiro: Imprensa Nacional, 1890.

CANABRAVA, Alice P. Um desembarque clandestino de escravos em Cananeia. In: Revista de História, v. 1, n. 1, p. 559-562, 1950.

CÂNDIDO, Mariana Pinho. Enslaving frontiers: slavery, trade, and identity in Benguela (1780-1850). Tese de Doutorado apresentada ao Programa de Pós-Graduação em História da York University. Toronto, Canadá, 2006.

CHALHOUB, Sidney. Visões da liberdade: as uiltimas décadas da escravidão na Corte. São Paulo: Companhia das Letras, 1990.

CHRISTOPHER, Emma. Slave ship sailors and their captive cargoes (1730-1807). New York: Cambridge University Press, 2006.

CONRAD, Robert E. World of sorrow: the African slave trade to Brazil. Baton Rouge: Louisiana University Press, 1986.

CORBIN, Alain. Le monde retrouvé de Louis-François Pinagot: sur les traces d'un inconnu. Paris: Flammarion, 1998.

ELTIS, David et alii. Transatlantic Slave Trade Database Online. www.slavevoyages.org.

ELTIS, David. Economic growth and the ending of the transatlantic slave trade. Oxford: Oxford University Press, 1987.

FLORENTINO, Manolo. Aspectos sociodemográficos da presença dos escravos moçambicanos no Rio de Janeiro, c.1790-c.1850. In: FRAGOSO, João L. R.; FLORENTINO, Manolo; SAMPAIO, Antonio Carlos Jucá; CAMPOS, Adriana Pereira (Orgs.). Nas rotas do império: eixos mercantis, tráfico e relaçôes sociais no mundo português. Vitória: Edufes; Lisboa: Instituto de Investigações Científicas e Tropicais; Brasília: CNPq, 2006, p. 193-244.

FRAGOSO, João L. R.; FERREIRA, Roberto Guedes. Tráfico de escravos, mercadores e fianças: dois bancos de dados (despachos de escravos, passaportes e licenças). Brasília: IPEA, 2001.

GINZBURG, Carlo. O nome e o como: troca desigual e mercado historiográfico. In: GINZBURG, Carlo (Org.). A micro-história e outros ensaios. Rio de Janeiro: Bertrand Brasil; Difel, 1989, p. 169-178.

O queijo e os vermes: o cotidiano e as ideias de um moleiro perseguido pela Inquisição. São Paulo: Companhia das Letras, 1989.

GRÃ-BRETANHA. $2 \& 3$ VIC cap. LXXIII. An act for the suppression of the slave trade. London, 1839.

GRINBERG, Keila. O fiador dos brasileiros: cidadania, escravidão e direito civil no tempo de Antônio Pereira Rebouças. Rio de Janeiro: Civilização Brasileira, 2002.

KARASCH, Mary. A vida dos escravos no Rio de Janeiro (1800-1850). São Paulo: Companhia das Letras, 2000. 
LEANDRO, José Augusto. Em águas turvas: navios negreiros na baía de Paranaguá. Esboços, Florianópolis, no 10, p. 99-117, 2003.

LEVI, Giovanni. Usos da biografia. In: FERREIRA, Marieta de Moraes; AMADO, Janaína (Orgs.). Usos e abusos da história oral. Rio de Janeiro: Ed. da FGV, 1996, p. 167-191.

LOOK LAI, Walton. Indentured labor, Caribbean sugar: Chinese and Indian migrants to the BritishWest Indies, 1838-1918. Baltimore: Johns Hopkins University Press, 1993.

MAMIGONIAN, Beatriz G. A harsh and gloomy fate: liberated Africans in the service of the Brazilian state, 1830s 1860s. In: CURRY, Dawne Y.; DUKE, Eric D.; SMITH, Marshanda (Orgs.). Extending the Diaspora: new scholarship on the history of black peoples. Champaign, IL: University of Illinois Press, 2009, p. 24-45.

. In the name of freedom: slave trade abolition, the law and the Brazilian branch of the African emigration scheme (Brazil-British West Indies, 1830s-1850s). Slavery \& Abolition, v. 30, no 1, p. 41-66, 2009.

. Revisitando o problema da "transição para o trabalho livre": a experiência dos africanos livres. In: FLORENTINO, Manolo. (Org.). Tráfico, cativeiro e liberdade (Rio de Janeiro, séculos XVII-XIX). Rio de Janeiro: Civilização Brasileira, 2005, p. 389-417.

. To be a liberated African in Brazil: labour and citizenship in the nineteenth century. Tese de Doutorado apresentada ao Programa de Pós-Graduação em História da University of Waterloo. Waterloo, Canadá, 2002.

. A Grã-Bretanha, o Brasil e as "complicações no estado atual da nossa população": revisitando a abolição do tráfico atlântico de escravos (1848-1851). Comunicação apresentada no IV Encontro Escravidão e Liberdade no Brasil Meridional. Curitiba, 2009.

MARTINEZ, Jenny S. Antislavery courts and the Dawn of International Human Rights Law. Yale Law Journal, v. 117, p. 550-641, 2008.

REBELATTO, Martha. Uma saída pelo mar: rotas de fuga escrava em Santa Catarina no século XIX. Revista de Ciências Humanas, Florianópolis, no 40, p. 423-442, 2006.

REIS, João José. Domingos Sodré, um sacerdote africano: escravidão, liberdade e candomblé na Bahia do século XIX. São Paulo: Companhia das Letras, 2008.

REVEL, Jacques. Microanálise e construção do social. In: REVEL, Jacques (Org.). Jogos de escalas: a experiência da microanálise. Rio de Janeiro: Ed. da FGV, 1998, p. 15-38.

ROCHA, Aurélio. Contribuições para o estudo das relações entre Moçambique e o Brasil - século XIX: tráfico de escravos, relações políticas e culturais. STVDIA, Lisboa, no 51, p. 61-118, 1992.

RODRIGUES, Jaime. De costa a costa: escravos, marinheiros e intermediários do tráfico negreiro de Angola ao Rio de Janeiro (1780-1860). São Paulo: Companhia das Letras, 2005.

O infame comércio: propostas e experiências no final do tráfico de escravos, 1800-1850. Campinas: Ed. da Unicamp; Cecult, 2000.

SCHULER, Monica. "Alas, Alas, Kongo": a social history of indentured African immigration into Jamaica, 1841 1865. Baltimore: The Johns Hopkins University Press, 1980.

Liberated Central Africans in nineteenth century Guiana. In: HEYWOOD, Linda M. (Org.). Central Africans and cultural transformations in the American diaspora. Cambridge: Cambridge University Press, 2002, p. 319-352.

SCOTT, Rebecca J. Degrees of freedom: Louisiana and Cuba after slavery. Cambridge, MA: Belknap Press of Harvard University Press, 2005.

SOARES, Carlos Eugênio Líbano. A capoeira escrava e outras tradiçôes rebeldes no Rio de Janeiro, 1808-1850. Campinas: Ed. da Unicamp; Centro de Pesquisa em História Social da Cultura, 2001.

SUBRAHMANYAM, Sanjay. Connected histories: notes towards a reconfiguration of early-Modern Eurasia. Modern Asian Studies, v. 31, no 3, p. 735-762, 1997.

TAVARES, Luís Henrique Dias. Comércio proibido de escravos. São Paulo: Ática, 1988.

Verbete "Landsmen" In: The Oxford Companion to Ships and the Sea. Oxford: Oxford University Press, 2006. Consultado em Encyclopedia.com. (Acesso 11/10/2009). http://www.encyclopedia.com/doc/1O225-landsmen.html.

VERGER, Pierre. Fluxo e refluxo do tráfico de escravos entre o golfo do Benin e a Babia de Todos os Santos dos séculos XVII a XIX. São Paulo: Corrupio, 1987. (Ed. original Haia e Paris: Mouton, 1968). 
José Majojo e Francisco Moçambique, marinheiros das rotas atlânticas: NOTAS SOBRE A RECONSTITUIÇÃO DE TRAJETÓRIAS DA ERA DA ABOLIÇÃO

Beatriz Gallotti Mamigonian

XAVIER, Regina C. L. A conquista da liberdade: libertos em Campinas na segunda metade do século XIX. Campinas: Centro de Memória da Unicamp, 1996.

\title{
RESUMO
}

Este artigo pretende-se um exercício de reconstituição de trajetórias de vida da era da abolição, a partir dos casos dos africanos José Majojo e Francisco Moçambique, marinheiros escravos do navio Dois de Fevereiro na rota Rio de Janeiro-Benguela, que foram emancipados e enviados para Trinidad depois que o navio foi apreendido pela Marinha Real britânica em 1841. Além de discutir a documentação gerada pela campanha de repressão ao tráfico de escravos empreendida pela Grä-Bretanha e outras fontes pertinentes, o artigo situa os dois personagens nos contextos conhecidos da história do Atlântico na era da abolição e propõe contextos novos, que, por sua vez, são iluminados pelas trajetórias desses africanos.

Palavras-chave: aboliçãa do tráfico de escravos, Grä-Bretanha, marinheiros escravos, micro-história.

\begin{abstract}
This essay aims to be an exercise in the reconstitution of life-histories from the age of abolition, using the cases of two African men, José Majojo and Francisco Moçambique, who were enslaved seamen on board the Dois de Fevereiro in the Rio de Janeiro-Benguela route and were emancipated and sent to Trinidad after the ship was apprehended by the Royal Navy in 1841. Besides discussing the documentation pertaining to the British campaign to suppress the slave trade and other relevant primary sources, the essay puts the two African men in the established contexts of the history of the Atlantic in the age of abolition and suggests new contexts that are illuminated by their trajectories.

Keywords: slave trade abolition, Great Britain, enslaved seamen, microhistory.
\end{abstract}

